\title{
The influence of posture on the estimation of daily salt intake by the second morning urine method
}

\author{
Minoru Kawamura, Tomoko Hashimoto, Masahiko Owada and Takashi Sugawara
}

The second morning urine (SMU) method was developed to evaluate daily salt intake, but the posture that should be adopted until the SMU collection remains unclear. This study investigated the influence of posture in hypertensive patients who underwent this test. The subjects were 100 patients who could collect 24-h urine samples correctly and were on a diet containing $7 \mathrm{~g}$ of salt per day. Their daily salt intake was estimated for three consecutive days in the recumbent, sitting, and sitting and standing positions (one posture each day). Estimated salt intake in the recumbent position $\left(10.9 \pm 2.4 \mathrm{~g} \mathrm{day}^{-1}\right)$ was higher than in the sitting position $\left(7.5 \pm 2.0 \mathrm{~g} \mathrm{day}^{-1}\right)$ and the sitting and standing position $\left(6.3 \pm 1.7 \mathrm{~g} \mathrm{day}^{-1}\right)$. The salt intake estimated in the sitting and standing position was similar to that obtained by $24-\mathrm{h}$ urine collection $\left(6.3 \pm 1.6 \mathrm{gday}^{-1}\right)$ and was significantly $(r=0.44, P<0.05)$ correlated with the $24-h$ urine value. The actual difference in estimated salt intake between the two methods was $0.0 \pm 1.7 \mathrm{~g} \mathrm{day}^{-1}$. There were no significant differences in estimated salt intake between the two methods in patients taking different classes of antihypertensive drugs. In conclusion, adopting the sitting and standing position until the SMU collection is important for the correct estimation of daily salt intake, and this method could replace the 24-h collection method because of its convenience, especially in outpatients.

Hypertension Research (2010) 33, 505-510; doi:10.1038/hr.2010.27; published online 5 March 2010

Keywords: antihypertensive drugs; salt intake; second morning urine method; 24-h urine collection

\section{INTRODUCTION}

Guidelines for the management of hypertension from various countries, ${ }^{1,2}$ including Japan, ${ }^{3}$ recommend the restriction of salt intake as an important dietary modification to lower blood pressure. The INTERSALT study ${ }^{4}$ estimated salt intake by 24 -h urine collection at 52 centers in 32 countries and showed that the mean daily salt intake was $9.2 \mathrm{~g}$ whereas the average value obtained from three Japanese centers was $11.0 \mathrm{~g}$, suggesting that the Japanese have a higher than average salt intake. Residents of Morioka in the Tohoku District of Japan have an even higher salt intake with a mean daily salt intake of approximately 13 g. ${ }^{5-7}$ This markedly exceeds the daily intake recommended by the Japanese guideline $(<6 \mathrm{~g}),{ }^{3}$ and salt restriction is especially important in areas with high salt intake, such as Morioka. Although the estimation of daily salt intake is important to provide appropriate advice about salt restriction, estimation by interview, the diary method, or 24-h urine collection is inconvenient for general use. $^{8}$ In fact, a survey showed that $88 \%$ of general physicians did not estimate the daily salt intake of hypertensive patients attending their outpatient clinics. ${ }^{9}$ Kawasaki et al. ${ }^{10}$ developed the second morning urine (SMU) method to evaluate daily salt intake from the second urine specimen collected in the morning before breakfast. This method is based on the assumption that 24 -h creatinine excretion can be predicted from demographic factors (sex, age, height and body weight), and the sodium:creatinine ratio of the 24 -h urine specimen is proportional to that of the SMU specimen. Accordingly, the 24-h sodium excretion is calculated as the sodium:creatinine ratio of the SMU specimen multiplied by the predicted 24 -h creatinine excretion. Daily sodium excretion values obtained by the SMU method show a strong correlation with those estimated by the 24-h collection $(R=0.73)$. The usefulness of the SMU method has been confirmed in population studies ${ }^{5,11,12}$ and in hypertensive patients. ${ }^{13}$ Although the posture that should be adopted for the SMU method was not specified by the original authors, ${ }^{10}$ posture is known to affect the urinary sodium:creatinine ratio ${ }^{14,15}$ and could possibly influence the estimation of daily salt intake by this method. Therefore, this study was designed to assess the effect of posture on the estimation of daily salt intake by the SMU method compared with the method of 24-h collection in hospitalized patients with hypertension on a saltrestricted diet.

\section{METHODS}

Subjects

We recruited patients with hypertension who were undergoing lifestyle modification (diet and exercise) as inpatients of our hospital. A total of 116 patients satisfied the following three criteria. First, they were assessed at our clinic during a 2-month period before admission, undergoing blood pressure measurements and laboratory tests. Second, their dietary salt intake was limited to $7 \mathrm{~g}$ daily during admission to the hospital. Third, sodium and creatinine 
excretion were measured by 24 -h urine collection at the end of the first hospital week. Approval for the study was granted by the ethics committee of the Iwate Prefectural Central Hospital. All subjects were given detailed information about the protocol before they agreed to enroll, and written consent was obtained in all cases.

\section{Procedures}

Before admission to the hospital, the blood pressure of each subject was measured at our outpatient clinic on at least three occasions, and blood and urine samples were collected before breakfast on at least one occasion. Figure 1 shows the protocol used to assess the validity of the SMU method. During hospital admission, patients were placed on a daily diet of $7 \mathrm{~g}$ of salt. Their daily salt intake was assessed by 24-h urine collection at the end of the first hospital week, as equilibration of the sodium balance requires approximately 1 week. ${ }^{16}$ On three consecutive days during the second week of admission, each patient arose at $0600 \mathrm{~h}$ and discarded the first voided urine. Then, the second voided urine was collected before breakfast at $0800 \mathrm{~h}$. Until the second voiding after awakening, patients remained in the recumbent position on the first day, in the sitting position on the second day, and in the sitting and standing position (both sitting and standing equally) on the third day. In the standing position, subjects were allowed to walk but not run. A 24-h urine collection was carried out with an Automatic Urine Collection System (PZ-50AZ; Koken, Tokyo) that allows fractional urine sampling. During admission, patients were advised to only adhere to the hospital diet and eat nothing else. Water and weak Japanese tea were available to drink ad libitum.

\section{Measurements and calculations}

Using the second voiding urine specimen, daily sodium excretion was measured by the SMU method, ${ }^{10}$ which utilizes the patient's gender, age, body weight, height, and the sodium and creatinine concentrations of the urine sample. As approximately $90 \%$ of a person's sodium intake is excreted in the urine, ${ }^{17}$ daily sodium excretion was considered to be equal to daily salt intake and was expressed as grams of sodium chloride $(\mathrm{NaCl})$ per day as suggested by the Japanese guideline. ${ }^{3}$ The formula for estimating the salt intake (grams of $\mathrm{NaCl}$ per day) was $0.96 \times((\mathrm{UNa} / \mathrm{UCr} / 10) \times \text { predicted daily creatinine excretion })^{0.5}$, where $\mathrm{UNa}$ is the urinary sodium concentration $\left(\mathrm{mEql}^{-1}\right)$, and $\mathrm{UCr}$ is the urinary creatinine concentration $\left(\mathrm{mg} 100 \mathrm{ml}^{-1}\right)$.

The formula ${ }^{18}$ for estimating daily creatinine excretion from demographic data was $15.1 \times$ body weight $(\mathrm{kg})+7.4 \times$ height $(\mathrm{cm})-12.6 \times$ age (years) -79.9 for men and $8.6 \times$ body weight $(\mathrm{kg})+5.1 \times$ height $(\mathrm{cm})-4.7 \times$ age (years) -75.0 for women. The 24 -h urine specimen was also used to calculate the daily excretion of sodium and creatinine. The albumin concentration of each urine specimen was measured by SRL Laboratories (Tokyo, Japan). Hypertension, diabetes and dyslipidemia were diagnosed according to the Japanese guidelines for hypertension, ${ }^{3}$ diabetes ${ }^{19}$ and atherosclerosis. ${ }^{20}$ Blood pressure was defined as the mean of the values obtained at the last two clinic appointments. Subjects who were already on antihypertensive medications were classified as having hypertension regardless of their actual blood pressure. When the calculated creatinine

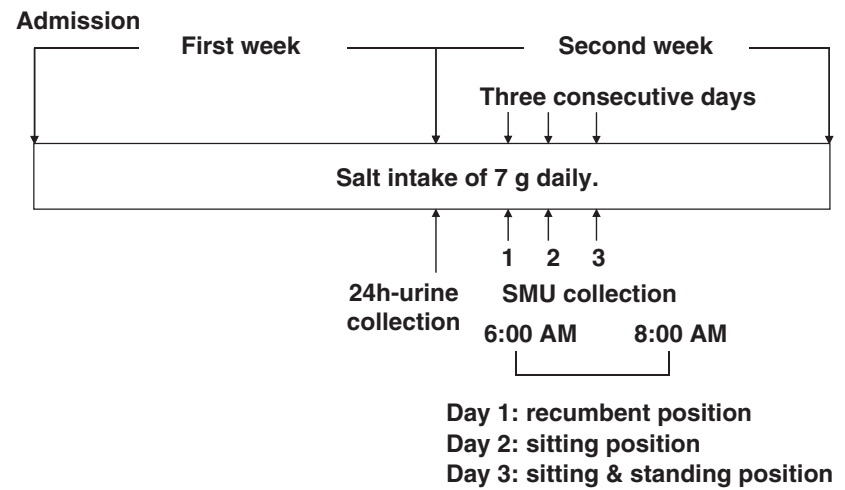

Figure 1 Protocol for assessing the validity of the second morning urine (SMU) method. excretion was outside $\pm 30 \%$ of the predicted creatinine excretion, patients were considered to have performed the urine collection incorrectly. ${ }^{21}$ A total of 16 patients had creatinine excretion values that were more than $30 \%$ below the predicted value, and these patients were excluded. Accordingly, 100 patients were subjected to further analysis.

\section{Statistical methods}

Results are expressed as mean \pm s.d. The $\chi^{2}$-test was used for the comparison of diabetes mellitus, dyslipidemia and administration (none, monotherapy and combination therapy) of antihypertensive drugs between men and women. Differences in other parameters between men and women were analyzed by the Mann-Whitney $U$-test. Differences between the three postures (recumbent, sitting, and sitting and standing) and differences between the SMU and 24-h urine data were analyzed by Wilcoxon's signed rank test. Correlations between the SMU and 24-h data were assessed by univariate analysis. In all analyses, a probability $(P)$ value of $<0.05$ was considered statistically significant.

\section{RESULTS}

Baseline characteristics of men and women in this study are presented in Table 1. Body weight, hemoglobin $\mathrm{A}_{1 \mathrm{c}}$ and serum creatinine were significantly higher in men than women whereas high-density lipoprotein cholesterol was significantly higher in women. The effect of posture on the estimation of salt intake from the second urine collection by the SMU method is shown in Table 2. For all 100 patients, the estimated salt intake was $10.9 \pm 2.4 \mathrm{gday}^{-1}$ in the recumbent position, $7.5 \pm 2.0 \mathrm{~g} \mathrm{day}^{-1}$ in the sitting position, and $6.3 \pm$ $1.7 \mathrm{~g} \mathrm{day}^{-1}$ in the sitting and standing position. It was found that assessment in the recumbent position led to the highest estimated salt intake, followed by assessment in the sitting position and then the sitting and standing position in both men and women. The estimated salt intake in the sitting and standing position was similar to that obtained from the $24-\mathrm{h}$ urine collection $\left(6.6 \pm 1.5 \mathrm{~g} \mathrm{day}^{-1}\right.$ for men, $6.0 \pm 1.6 \mathrm{~g} \mathrm{day}^{-1}$ for women, and $6.3 \pm 1.6 \mathrm{~g} \mathrm{day}^{-1}$ for all patients). Figure 2 shows that the estimated salt intake obtained by 24 -h urine collection was not significantly different from that estimated by the SMU method in the sitting and standing position but was significantly lower than that obtained in the sitting position or the recumbent position for both men and women. As there were no significant differences between men and women with regard to the estimated salt

\section{Table 1 Baseline characteristics of the patients}

\begin{tabular}{|c|c|c|}
\hline Variable & Men & Women \\
\hline Number & 53 & 47 \\
\hline Age (years) & $58 \pm 14$ & $61 \pm 12$ \\
\hline Body weight (kg) & $69.2 \pm 12.5$ & $58.7 \pm 12.9 *$ \\
\hline Body mass index $\left(\mathrm{kg} \mathrm{m}^{-2}\right)$ & $24.8 \pm 3.8$ & $25.2 \pm 5.1$ \\
\hline Systolic blood pressure (mm Hg) & $143 \pm 14$ & $144 \pm 14$ \\
\hline Diastolic blood pressure (mm Hg) & $83 \pm 10$ & $81 \pm 9$ \\
\hline Hemoglobin $A_{1 c}(\%)$ & $8.1 \pm 1.8$ & $7.3 \pm 2.0^{*}$ \\
\hline Low-density lipoprotein cholesterol (mg $100 \mathrm{ml}^{-1}$ ) & $116 \pm 31$ & $121 \pm 31$ \\
\hline High-density lipoprotein cholesterol (mg $100 \mathrm{ml}^{-1}$ ) & $46 \pm 15$ & $56 \pm 17^{*}$ \\
\hline Triglycerides (mg $100 \mathrm{ml}^{-1}$ ) & $116 \pm 31$ & $119 \pm 64$ \\
\hline Creatinine (mg $100 \mathrm{ml}^{-1}$ ) & $0.85 \pm 0.24$ & $0.57 \pm 0.19 *$ \\
\hline Urinary albumin ( $\mathrm{mgg}^{-1}$ creatinine) & $100 \pm 229$ & $101 \pm 210$ \\
\hline Diabetes mellitus, number (\%) & $44(83)$ & $28(88)$ \\
\hline Dyslipidemia, number (\%) & $37(70)$ & $18(56)$ \\
\hline \multicolumn{3}{|l|}{ Antihypertensive drugs } \\
\hline None, number (\%) & $13(25)$ & 9 (19) \\
\hline Monotherapy, number (\%) & $24(45)$ & $21(45)$ \\
\hline Combination therapy, number (\%) & $16(30)$ & $17(36)$ \\
\hline
\end{tabular}

${ }^{*} P<0.05$ compared with men by the Mann-Whitney $U$-test. 
Table 2 Influence of posture on the estimated daily salt intake obtained by the second morning urine method

\begin{tabular}{|c|c|c|c|c|}
\hline Sex & Parameter & Recumbent position & Sitting position & Sitting and standing position \\
\hline \multirow[t]{3}{*}{ Men } & Sodium $\left(m E q I^{-1}\right)$ & $83.1 \pm 36.2^{*, * *}$ & $75.7 \pm 35.7^{*}$ & $66.2 \pm 25.7$ \\
\hline & Creatinine $\left(\mathrm{mg} 100 \mathrm{ml}^{-1}\right)$ & $110.2 \pm 62.3^{*, * *}$ & $194.1 \pm 98.4^{*}$ & $242.3 \pm 104.4$ \\
\hline & Intake $\left(\right.$ gday $\left.^{-1}\right)$ & $10.4 \pm 2.5^{*, * *}$ & $7.5 \pm 2.0^{*}$ & $6.2 \pm 1.7$ \\
\hline \multirow[t]{2}{*}{ Women } & Sodium $\left(m E q I^{-1}\right)$ & $86.3 \pm 40.8^{*, * *}$ & $76.2 \pm 28.6^{*}$ & $72.3 \pm 25.6$ \\
\hline & Intake $\left(\right.$ g day $\left.^{-1}\right)$ & $11.4 \pm 2.3^{*, * *}$ & $7.4 \pm 2.1^{*}$ & $6.5 \pm 1.7$ \\
\hline
\end{tabular}

Sodium and creatinine are expressed as concentrations of second voided urine samples for measurements of daily salt intake.

Salt intake is expressed as $\mathrm{g}$ of $\mathrm{NaCl}$ per day. ${ }^{*} P<0.05$ vs. sitting and standing, ${ }^{* *} P<0.05$ vs. sitting by the Wilcoxon signed-rank test.

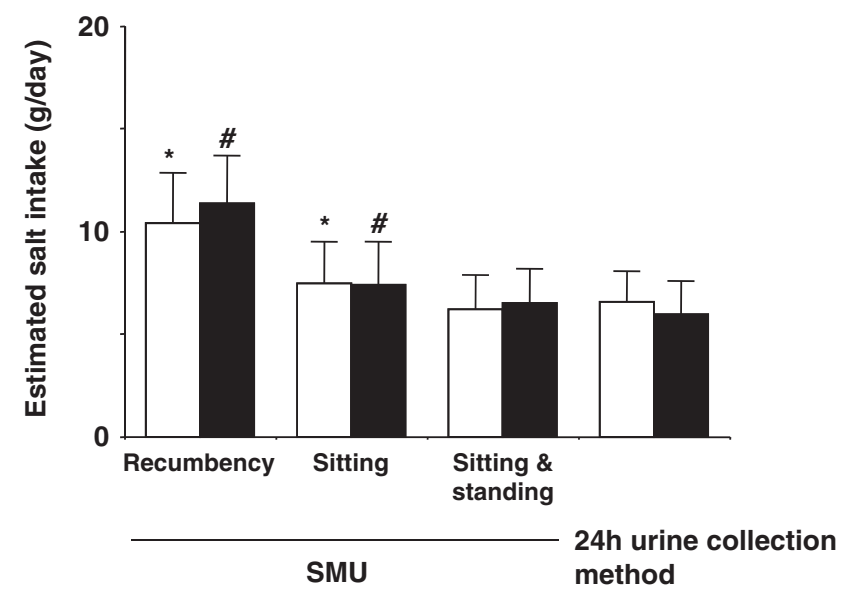

Figure 2 Comparison of salt intake estimated by the second morning urine (SMU) method with various postures and the 24-h urine collection method in men (open columns) and women (closed columns). ${ }^{*} P<0.05$ vs. $24-\mathrm{h}$ urine in men, ${ }^{\#} P<0.05$ versus 24 -h urine in women by the Wilcoxon signed-rank test.

intake obtained by the SMU method with any posture or by $24-\mathrm{h}$ collection, we carried out further data analysis for men and women combined. The predicted creatinine excretion showed a strong correlation $(r=0.92, P<0.01)$ with the creatinine excretion measured by 24-h urine collection (Figure 3, left). The actual difference in creatinine excretion between the two methods was $16 \pm 154 \mathrm{mg} \mathrm{day}^{-1}$. The salt intake estimated by the SMU method with the sitting and standing posture also showed a significant correlation $(r=0.44$, $P<0.01$ ) with that obtained by 24 -h urine collection (Figure 3, right), and the actual difference of salt intake between the two methods was $0.0 \pm 1.7 \mathrm{~g} \mathrm{day}^{-1}$.

The effect of antihypertensive therapy on the estimation of salt intake by the SMU method in the sitting and standing position was assessed by comparison with the 24 -h collection method. The following antihypertensive drugs were being used: calcium channel blockers (daily doses: amlodipine 5-10 mg, manidipine $20-40 \mathrm{mg}$, cilnidipine $10-20 \mathrm{mg}$, benidipine $4-8 \mathrm{mg}$ and nifedipine retard $20-60 \mathrm{mg}$ ), angiotensin II receptor blockers (candesartan $8 \mathrm{mg}$, losartan $25 \mathrm{mg}$, telmisartan 40-80 mg, olmesartan $20 \mathrm{mg}$ and valsartan $80-160 \mathrm{mg}$ ), diuretics (indapamide $0.5-1 \mathrm{mg}$ ), angiotensin-converting enzyme inhibitors (enalapril 5-10 mg and imidapril 5-10 mg), $\beta$-blockers (atenolol 25-50 mg, betaxolol $10-20 \mathrm{mg}$ and bisoprolol $5 \mathrm{mg}$ ), $\alpha$-blockers (doxazosin $2-4 \mathrm{mg}$ and urapidil $60 \mathrm{mg}$ ), $\alpha / \beta$-blockers (carvedilol $5 \mathrm{mg}$ ), central sympatholytic agents (guanabenz 1-2 mg) and a combined preparation (losartan $50 \mathrm{mg}$ and hydrochlorthiazide $12.5 \mathrm{mg}$ ). The diuretics and the combined preparation were administered once daily in the morning; the central sympatholytic agent and $\alpha / \beta$-blocker were administered twice a day (morning and evening); and the other antihypertensive drugs were administered in the morning or in the morning and evening. There were no significant differences in the estimated salt intake between the SMU and 24-h collection methods among patients without antihypertensive therapy $\left(6.9 \pm 1.4 \mathrm{~g} \mathrm{day}^{-1}\right.$ vs. $\left.6.9 \pm 1.6 \mathrm{~g} \mathrm{day}^{-1}\right)$, patients on monotherapy $\left(6.1 \pm 1.7 \mathrm{~g} \mathrm{day}^{-1}\right.$ vs. $\left.6.3 \pm 1.5 \mathrm{~g} \mathrm{day}^{-1}\right)$ and patients on combination therapy $\left(6.3 \pm 1.7 \mathrm{~g} \mathrm{day}^{-1}\right.$ vs. $\left.6.3 \pm 1.6 \mathrm{~g} \mathrm{day}^{-1}\right)$. The patients were also divided into six groups by the different classes of antihypertensive drugs. Angiotensin II receptor blockers and/or angiotensin-converting enzyme inhibitors were used by 55 patients, calcium channel blockers by 43 patients, diuretics by 13 patients, $\beta$-blockers by 10 patients, $\alpha$ blockers by 9 patients and central sympatholytic agents by 5 patients. Patients who took the $\alpha / \beta$-blocker were counted in both the $\alpha$-blocker group and the $\beta$-blocker group. Patients who received the combined preparation were counted in both the angiotensin II receptor blockers group and the diuretic group. There were no significant differences in the estimated salt intake between the SMU and 24-h collection methods in the angiotensin II receptor blockers and/or angiotensinconverting enzyme inhibitors group $\left(6.2 \pm 1.7 \mathrm{~g} \mathrm{day}^{-1}\right.$ vs. $6.2 \pm$ $\left.1.5 \mathrm{~g} \mathrm{day}^{-1}\right)$, the calcium channel blocker group $\left(6.2 \pm 1.9 \mathrm{~g} \mathrm{day}^{-1} v \mathrm{v}\right.$. $\left.6.1 \pm 1.5 \mathrm{~g} \mathrm{day}^{-1}\right)$, the diuretic group $\left(5.7 \pm 1.8 \mathrm{~g} \mathrm{day}^{-1}\right.$ vs. $5.3 \pm 1.7$ $\left.\mathrm{g} \mathrm{day}^{-1}\right)$, the $\beta$-blocker group $\left(5.6 \pm 1.0 \mathrm{~g} \mathrm{day}^{-1}\right.$ vs. $\left.5.7 \pm 1.5 \mathrm{~g} \mathrm{day}^{-1}\right)$, the $\alpha$-blocker group $\left(6.5 \pm 1.7 \mathrm{~g} \mathrm{day}^{-1}\right.$ vs. $\left.6.4 \pm 1.5 \mathrm{~g} \mathrm{day}^{-1}\right)$ and the central sympatholytic group $\left(6.4 \pm 1.7 \mathrm{~g} \mathrm{day}^{-1}\right.$ vs. $\left.6.8 \pm 1.1 \mathrm{~g} \mathrm{day}^{-1}\right)$ (Figure 4).

\section{DISCUSSION}

Although 24-h urine collection is considered to be the most reliable method for assessing daily salt intake, ${ }^{4,8,10}$ complete and accurate collection is not easy to achieve. We excluded 16 patients with incomplete collection and a deviation of creatinine excretion by more than $30 \%$ of the predicted value and then compared the SMU and 24-h collection methods in 100 hypertensive patients with a daily salt intake of $7 \mathrm{~g}$ during hospital admission. Our findings clearly indicated that the posture adopted until the collection of the SMU influenced the estimate of the daily salt intake by the SMU method. Data obtained in the sitting and standing position were most similar to the salt intake obtained by $24-\mathrm{h}$ urine collection, so adoption of the sitting and standing position was important for the accurate 


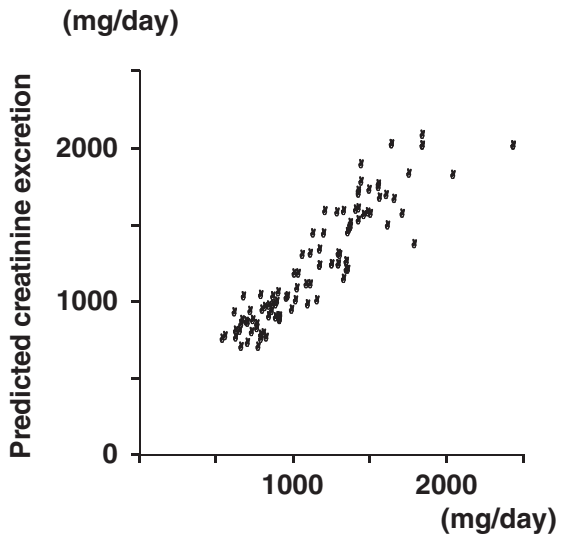

Measured creatinine excretion

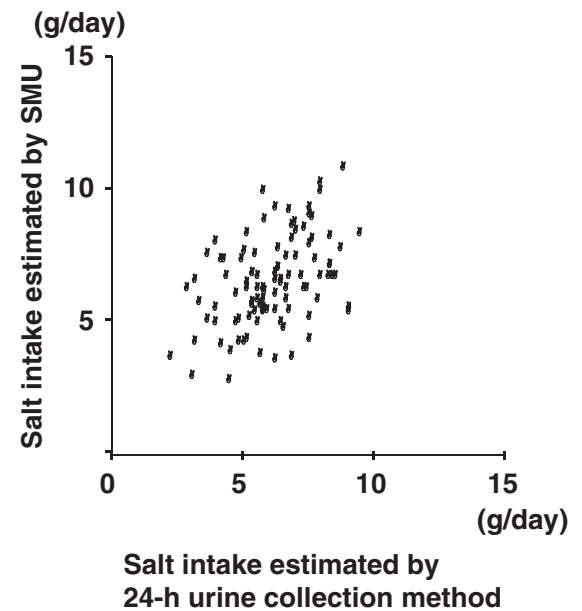

24-h urine collection method

Figure 3 Correlation between predicted creatinine excretion and measured creatinine excretion $(r=0.92, P<0.05)$ (left panel). Correlation between salt intake estimated by the second morning urine (SMU) method and the 24-h urine collection method $(r=0.44, P<0.05)$ (right panel). The plots show data from 100 hypertensive patients. Salt intake was estimated by the SMU method in the sitting and standing position.

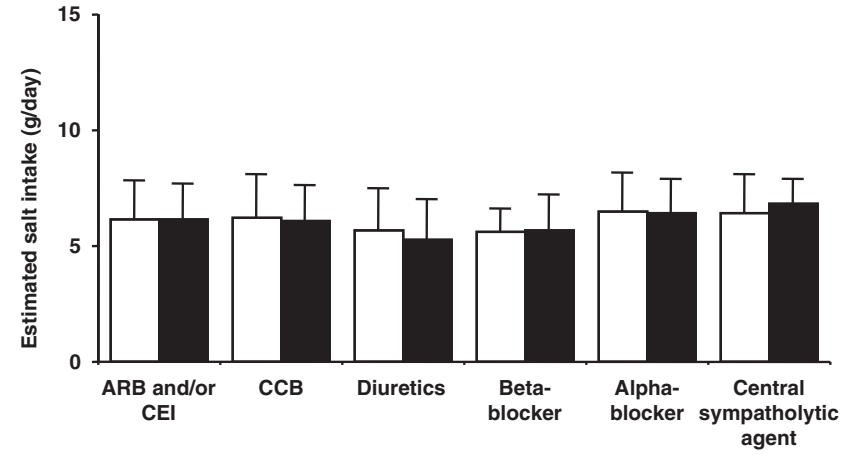

Figure 4 Effect of each class of antihypertensive agents on the estimation of daily salt intake by the second morning urine (SMU) method (open columns) or the 24-h urine collection method (closed columns). There were no significant differences in the estimated salt intake between the two methods (Wilcoxon's signed-rank test). ACE-I, angiotensin-converting enzyme inhibitors; ARB, angiotensin II receptor blockers; CCB, calcium channel blockers.

estimation of salt intake by this method, and salt intake was overestimated in the recumbent position. There are several possible mechanisms by which changes in urinary sodium excretion occur in response to postural changes. Standing up from the recumbent position causes fluid to shift into the interstitial spaces in the lower limbs ${ }^{22}$ and results in an increase in colloid osmotic pressure, which leads to a decrease in the glomerular filtration rate and an increase in the fractional tubular reabsorption of sodium. ${ }^{23}$ Standing also alters sympathetic tone $e^{24,25}$ and the production of hormones related to the sodium balance, including the renin-angiotensin system, ${ }^{26}$ endothe$\operatorname{lin}^{27}$ and atrial natriuretic peptide, ${ }^{28}$ resulting in changes in urinary sodium excretion.

The SMU method was originally developed using healthy subjects ${ }^{10}$ who did not lie down after awakening until the SMU collection. To examine whether the SMU method is applicable for hypertensive patients, previous clinical studies have been done using hospital patients on a constant salt intake, but these patients often spend a considerable amount of time in bed and tend to lie down until voiding the SMU, resulting in an overestimation of salt intake. This may also help to explain why the SMU method is not widely used to estimate the salt intake of hypertensive patients at present. Owing to a difference of approximately $1 \mathrm{~g}$ daily between the salt intake obtained in the sitting position versus the sitting and standing position, and because of daily salt intake that varies in normal life, ${ }^{29}$ it is not practical to advise outpatients undergoing this test to spend their time equally in the sitting position and standing position; however, it is useful to advise them not to lie down. In the Japanese guideline, a spot urine method developed by Tanaka et al..$^{30}$ is recommended for the general estimation of daily salt intake because urine collection can be done at any time to measure the sodium:creatinine ratio. However, the estimation of salt intake by the spot urine method could also be affected by the posture adopted before urine collection.

This study indicated that the formula predicting daily creatinine excretion for healthy subjects was also applicable to hypertensive patients because the values calculated with the formula strongly correlated with the measured value for creatinine excretion (Figure 3, left). The correlation of estimated salt intake between the SMU method and the 24-h urine method was significantly weaker in our hypertensive patients $(r=0.44)$ than that reported in healthy subjects $(r=0.73) .{ }^{10}$ This difference may be related to the measurement conditions (a single measurement versus the mean value of three to five measurements) or the admission status (hospitalized versus not hospitalized). Hypertensive patients can be divided into dippers and non-dippers based on the circadian rhythm of their blood pressure and the change of sodium excretion, which differs between these two types because of movement from the supine to upright position, ${ }^{31}$ so the heterogeneity of our subjects may explain the weaker correlation in this study.

Calcium channel blocker, ${ }^{32}$ angiotensin-converting enzyme inhibitors $^{33}$ and diuretics all have a natriuretic effect that could potentially influence the estimation of daily salt intake by the SMU method by altering the circadian rhythm of sodium secretion. ${ }^{34}$ However, this method can actually be used in patients receiving antihypertensive therapy because there were no differences between the SMU and 24-h collection methods for any class of antihypertensive (Figure 4). These findings agreed with our previous results. ${ }^{13}$ Chronic administration of diuretics was considered most likely to interfere with the SMU method because these drugs have the strongest natriuretic effect among 
antihypertensive agents. However, diuretics were used at comparatively low doses (indapamide $0.5-1 \mathrm{mg} \mathrm{day}^{-1}$ and hydrochlorthiazide $12.5 \mathrm{mg} \mathrm{day}^{-1}$ ) probably because the Japanese guideline ${ }^{3}$ recommends low-dose diuretic therapy to avoid adverse effects. The SMU method was carried out to assess salt intake at $24 \mathrm{~h}$ after diuretic administration in this study, which may have allowed useful data to be obtained in patients taking diuretics, but further studies will be necessary to examine the influence of higher doses of diuretics.

Although the SMU method seems to be applicable to most hypertensive patients, it theoretically cannot be used in some patients. In patients who have muscle atrophy, such as those with long-term bed rest, the SMU method cannot be employed because the predicted value may overestimate their actual creatinine excretion. Also, if the sodium:creatinine excretion ratio of the second morning urine is not correlated with the ratio for the 24-h urine, the SMU method cannot be applied. A change of posture from the recumbent position increases the re-absorption of sodium by the renal tubules mainly through sympathetic nerve stimulation. ${ }^{24,25}$ Patients with autonomic neuropathy, such as diabetic neuropathy and/or patients with renal tubular dysfunction, for example, interstitial nephritis, may not be appropriate for the SMU method. Further studies are needed to determine the patients who should be excluded from the SMU method to enhance reliability.

There were several limitations of our study. We only examined the reliability of the SMU method in patients with a daily salt intake of $7 \mathrm{~g}$, so investigation at a higher salt intake is also needed. We previously studied $^{35} 22$ patients with essential hypertension who had a salt intake of $17 \mathrm{~g}$ per day, followed by $7 \mathrm{~g}$ per day for 1 week each. The salt intake estimated at the end of each week by the SMU method was $8.0 \pm 1.9 \mathrm{~g} \mathrm{day}^{-1}$ and $16.2 \pm 2.3 \mathrm{~g} \mathrm{day}^{-1}$, respectively, although the posture adopted until the second urine collection was not specified. These findings suggest that the SMU method is effective for estimating a higher salt intake. We examined the effect of three different postures on the estimation of salt intake by the SMU method, but the order was not randomized to avoid errors, so bias was possible. Although the dietary salt intake was set at $7 \mathrm{~g} \mathrm{day}^{-1}$ during admission, there was a comparatively wide range of salt intake (2.5-9.7 g) shown by the 24 -h urine collection method. The patient with the lowest intake did not eat miso soup containing $0.5 \mathrm{~g}$ of salt and did not use soy sauce containing salt as seasoning. If the study had been carried out in a metabolic ward, more precise results may have been obtained. This study was carried out in patients who wanted to initiate lifestyle modifications with diet and exercise, and they had relatively mild target organ damage. It remains unclear whether this method would be applicable in patients with severe target organ damage or an accelerated phase of hypertension.

In conclusion, the posture adopted before the second morning collection influenced the estimation of daily salt intake by the SMU method when the effect of posture was examined in inpatients with restricted salt intake $\left(7 \mathrm{~g} \mathrm{day}^{-1}\right)$. Maintaining the sitting and standing position until the SMU collection is advised to correctly estimate daily salt intake by the SMU method, and it is important for patients not to lie down. This method can be used in patients receiving antihypertensive therapy because there were no differences between the SMU and 24 -h collection methods in patients receiving various drugs. The SMU method may replace the 24 -h urine collection method because of its greater convenience, especially in outpatient clinics.

\section{ACKNOWLEDGEMENTS}

We thank Dr Terukazu Kawasaki for his valuable comments and Ms Kazumi Yamamoto for her excellent clerical support.
1 Chobanian AV, Bakris GL, Black HR, Cushman WC, Green LA, Izzo Jr IL, Jones DW, Materson BJ, Oparil S, Wright Jr JT. The seventh report of the joint national committee on prevention, detection, evaluation, and treatment of high blood pressure. JAMA 2003; 289: 2560-2572.

2 Mancia G, De Backer G, Dominiczak A, Cifkova R, Fagard R, Germano G, Grassi G, Heagarty A, Kjeldsen SE, Laurent S, Narkiewicz K, Boudier HAJS, Zanchetti A. The task force for the management of arterial hypertension of the European Society of Hypertension (ESH) and of the European Society of Cardiology (ESC). 2007 Guidelines for the management of arterial hypertension. J Hypertens 2007; 25: $1105-1187$

3 Ogihara T, Kikuchi K, Matsuoka H, Fujita T, Higaki J, Horiuchi M, Imai Y, Imaizumi T, Ito S, Iwao H, Kario K, Kawano Y, Kim-Mitsuyama S, Kimura G, Matsubara H, Matsuura H, Naruse M, Saito I, Shimada K, Shimamoto K, Suzuki H, Takishita S, Tanahashi N, Tsuchihashi T, Uchiyama M, Umemura S, Ishimitsu T, Rakugi H. The Japanese Society of Hypertension guidelines for the management of hypertension. Hypertens Res 2009; 32: 3-107.

4 Intersalt Cooperative Research Group. Intersalt: an international study of electrolyte excretion and blood pressure. Results for $24 \mathrm{~h}$ urinary sodium and potassium excretion. BMJ 1988; 297: 319-328.

5 Hashimoto T, Yagami F, Owada M, Sugawara T, Kawamura M. Salt preference according to a questionnaire vs. dietary salt intake estimated by a spot urine method in participants at a health- checkup center. Intern Med 2008; 47: 399-403.

6 Kawamura M, Kimura Y, Takahashi K, Satoh N, Oku K, Adachi T, Nakajima J, Murooka M, Fujiwara T, Hiramori K. Relation of urinary sodium excretion to blood pressure, glucose metabolism, and lipid metabolism in residents of an area of Japan with high sodium intake. Hypertens Res 1997; 20: 287-293.

7 Nakajima J, Kawamura M, Fujjiwara T, Hiramori K. Body height is a determinant of seasonal blood pressure variation in patients with essential hypertension. Hypertens Res 2000; 23: 587-592.

8 Kawano Y, Tsuchihashi T, Matsuura H, Ando K, Fujita T, Ueshima H. Report of the working group for dietary salt reduction of the Japanese Society of Hypertension: (2) Assessment of salt intake in the management of hypertension. Hypertens Res 2007; 30: 887-893.

9 Etoh T. Results of a self-administered questionnaire for salt restriction program among participant doctors of educational meeting for hypertension. Bull Jpn Soc Hypertens 2006; 30: 8-10.

10 Kawasaki T, Itoh K, Uezono K, Sasaki H. A simple method for estimating $24 \mathrm{~h}$ urinary sodium and potassium excretion from second morning voiding urine specimen in adults. Clin Exp Pharmacol Physiol 1993; 20: 7-14.

11 Kawasaki T, Itoh K, Uezono K, Ogaki T, Yoshimizu Y, Kobayashi S, Osaka T, Ogata M, Dhungel S, Sharma S, Acharya GP. Investigation of high salt intake in a Nepalese population with low blood pressure. J Hum Hypertens 1993; 7: 131-140.

12 Iseki K, Iseki C, Itoh K, Uezono K, Sanefuji M, Ikemiya Y, Fukiyama K, Kawasaki T. Urinary excretion of sodium and potassium in a screened cohort in Okinawa, Japan. Hypertens Res 2002; 25: 731-736.

13 Kawamura M, Kusano Y, Takahashi T, Owada M, Sugawara T. Effectiveness of a spot urine method in evaluating daily salt intake in hypertensive patients taking oral antihypertensive drugs. Hypertens Res 2006; 29: 397-402.

14 Adachi T, Kawamura M, Owada M, Hiramori K. Effect of age on renal functional and orthostatic vascular response in healthy men. Clin Exp Pharmacol Physiol 2001; 28: 877-880.

15 Kawasaki T, Kawamura M, Ito K. Second morning urine method developed for estimating daily sodium and potassium excretion. J Metab Clin Nutr 2008; 11: 237-253.

16 Kawasaki T, Delea CS, Bartter FC, Smith H. The effect of high-sodium and low-sodium intakes on blood pressure and other related variables in human subjects with idiopathic hypertension. Am J Med 1978; 64: 193-198.

17 Holbrook JT, Patterson KY, Bodner JE, Douglas LW, Veillon C, Kelsay JL, Mertz W, Smith Jr JC. Sodium and potassium intake and balance in adults consuming self-selected diets. Am J Clin Nutr 1984; 40: 786-793.

18 Kawasaki T, Uezono K, Itoh K, Ueno M. Prediction of 24-h urinary creatinine excretion from age, body weight, and height of an individual and its application. Jpn J Pub Health 1991; 38: 567-574.

19 Kuzuya K, Nakagawa S, Satoh J, Kanazawa T, Iwamoto Y, Kobayashi M, Nanjo K, Sasaki A, Seino Y, Ito C, Shima K, Nonaka K, Kadowaki T. Report of the Committee of Japan Diabetes Society on the classification and diagnostic criteria of diabetes mellitus. J Japan Diabetes Soc 1999; 42: 385-404.

20 Japan Atherosclerosis Society. Japan Atherosclerosis Society Guidelines for Prevention of Atherosclerotic Cardiovascular Diseases. Kyowa Kikaku: Tokyo, 2007, 11-13.

21 Hashimoto T, Yagami F, Owada M, Sugawara T, Kawamura M. Application of a formula to predict 24-h urinary excretion of creatinine in obese patients. Med J Iwate Pref Hosp 2008; 48: 14-18.

22 Blomqvist CG, Stone HL. Cardiovascular adjustments to gravitational stress: the cardiovascular system. In Stephard JT, Abboud FM (eds). Handbook of Physiolgy, Vol. 3 Williams Wilkins: Baltimore, 1983, 1025-1063.

23 Knox FG, Mertz JI, Burnett Jr JC, Haramati A. Role of hydrostatic and oncotic pressures in renal sodium reabsorption. Circ Res 1983; 52: 491-500.

24 Dibona GF, Johns EJ. A study of the role of renal nerves in the renal responses to head-up tilt in the anaesthetized dog. J Physiol 1980; 299: 117-126. 
25 Yo Y, Nagano M, Nagano N, liyama K, Higaki J, Mikami H, Ogihara T. Effects of age and hypertension on autonomic nervous regulation during passive head-up tilt. Hypertension 1994; 23(suppl I): 82-86.

26 Hesse B, Ring-Larsen H, Nielsen I, Christensen NJ. Renin stimulation by passive tilting: the influence of an anti-gravity suit on postural changes in plasma renin activity, plasma noradrenaline concentration and kidney function in normal man. Scand J Clin Lab Invest 1978; 38: 163-169.

27 White M, Courtemanche M, Stewart DJ, Talajic M, Mikes E, Cernacek P, Vantrimpont P, Leclerc D, Bussieres L, Rouleau JL. Age- and gender-related changes in endothelin and catecholamine release, and in autonomic balance in response to head-up tilt. Clin Sci 1997; 93: 309-316.

28 Grandis DJ, Uretsky BF, Ray SM, Vassilaros L, Verbalis JG, Puschett JB. Differential effects of atrial natriuretic peptide infusion at physiological doses in different postures in humans. Am J Hypertens 1993; 4: 219-227.

29 Kawasaki T, Ueno M, Uezono K, Kawazoe N, Nakamuta B, Ueda K, Omae T. Average urinary excretion of sodium in 24 hours can be estimated from a spot urine specimen. Circ J 1982; 46: 948-953.
30 Tanaka T, Okamura T, Miura K, Kadowaki T, Ueshima H, Nakagawa H, Hashimoto T. A simple method to estimate populational 24-h urinary sodium and potassium excretion using a casual urine specimen. J Hum Hypertens 2002; 16: 97-103.

31 Uzu T, Takeji M, Yamauchi A, Kimura G. Circadian rhythm and postural change in natriuresis in non-dipper type of essential hypertension. J Hum Hypertens 2001; 15: 323-327.

32 limura 0, Shimamoto K. Efficacy and mode of action of manidipine; a new calcium antagonist. Am Heart J 1993; 125: 635-641.

33 Ramirez G, Gangury A, Brueggemeyer CD. Acute effect of captopril on aldosterone secretory response to endogenous or exogenous adrenocorticotropin. J Clin Endocrinol Metab 1988; 66: 46-50.

34 Kawasaki T, Uezono K, Ueno M, Omae T, Matsuoka M, Haus E, Halberg F. Comparison of circadian rhythms of the renin-angiotensin-aldosterone system and electrolytes in clinically healthy young women in Fukuoka and Minnesota. Acta Endocrinol 1983; 102: 246-251.

35 Hashimoto T, Owada M, Sugawara T, Kawamura M. The estimated salt intake by Kawasaki's method in response to a change in salt intake in patients with hypertension. J Blood Pressure 2007; 14: 83-84. 